\title{
Site selectivities in fluorination.
}

Syo Ishida ${ }^{a}$, Tom Sheppard*b, Takashi Nishikata*a

a Graduate School of Sciences and Technology for innovation, Yamaguchi University, Ube, Yamaguchi, 755-8611, Japan

b Department of Chemistry, University College London, Christopher Ingold Laboratories, 20 Gordon Street, London, WC1H OAJ, U.K.

Key words: Fluorination, site-selective, catalyst

Abstract

In the synthesis of bio-active compounds, fluorinated compounds play a prominent role. However, the site-selective fluorination of organic molecules is often challenging, because activation of a reaction site using a fluorinating reagent can be difficult in a substrate possessing many functional groups. This digest introduces recent examples of site-selective fluorination reactions.

Contents

Introduction

Site-selective fluorination of hydroxy groups

Site-selective fluorination of alkyl halides

Site-selective fluorination of allylic halides

Site-selective fluorination of $\mathrm{C}-\mathrm{H}$ bonds

Alkane $\mathrm{C}-\mathrm{H}$ bonds

Allylic $\mathrm{C}-\mathrm{H}$ bonds

Benzylic C-H bonds

Aryl C-H bonds

Introduction

Organic molecules containing one or more fluorine atoms are undoubtedly useful and important. According to the literature ${ }^{[1]}$, approximately $30 \%$ of all agrochemicals and $20 \%$ of all pharmaceuticals contain a fluorine atom. For example, the antidepressant fluoxetine (Prozac) ${ }^{[2]}$, the cholesterol-lowering drug atorvastatin (Lipitor) ${ }^{[3]}$, and the antibacterial ciprofloxacin (Ciprobay) ${ }^{[4]}$ are well-known fluorinated pharmaceuticals.

To synthesize complex fluorinated molecules, the development of highly selective fluorination reactions is required. The main fluorination methods are electrophilic and nucleophilic reactions ${ }^{[5,6]}$, but more recently reports of radical fluorination reactions have emerged ${ }^{[7-9]}$ (Scheme 1). Judging from those three reaction patterns, the fundamental theory of fluorinations has already been established, and there are already many well-established fluorinating reagents e.g. SelectFluor ${ }^{[10]}$ and DAST (diethylaminosulfur trifluoride) ${ }^{[11]}$.

$\mathrm{R}-\mathrm{X} \underset{\begin{array}{l}\text { Electrophilic } \\ \text { Nucleophilic } \\ \text { Radical }\end{array}}{\stackrel{\mathrm{F} \text { source }}{\longrightarrow} \mathrm{R}-\mathrm{F} \quad \begin{array}{l}\mathrm{X}=\mathrm{H}, \mathrm{O}, \\ \text { halogen... }\end{array}}$

Scheme 1

Although various types of fluorination reactions including $\mathrm{C}-\mathrm{H}$ fluorination and enantioselective reactions with designer fluorinating reagents have been reported ${ }^{[10-12]}$, the core issue is to develop more efficient reactions for $\mathrm{C}-\mathrm{F}$ bond formation 
addressing the problem of site selectivity with a substrate possessing multiple reaction sites (Scheme 2). In this digest, we attempt to provide an overview of selected recent reports of site-selective fluorination, together with our insights. We have decided to focus on fluorination reactions which lead to incorporation of a single fluorine atom alone, and not to include related transformations such as fluoro-functionalization where both a fluorine atom and another element are introduced simultaneously. This digest is not intended to be a comprehensive review of recent developments, but simply to introduce a selection of key methods for achieving site selective fluorination reactions.

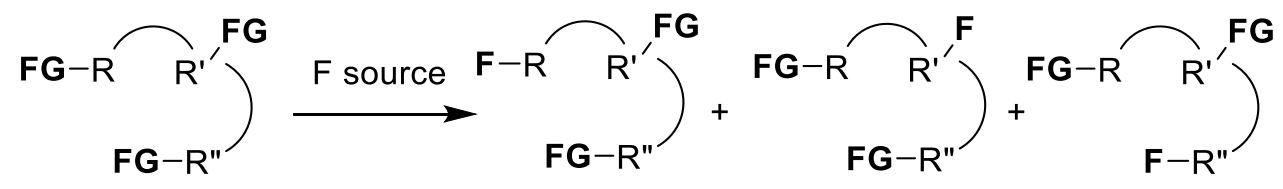

Scheme 2

\section{Site-selective fluorination of hydroxy groups}

The direct substitution of a hydroxy group with a fluorine atom provides aryl- or alkyl fluorides from phenols or alcohols, a so-called deoxyfluorination reaction. Ritter's group has invented a new deoxyfluorinating reagent, PhenoFluor (1) ${ }^{[13]}$. This reagent enables direct substitution of the hydroxy group of both electron-poor and -rich phenols in the presence of $\mathrm{CsF}$ (Scheme 3). Although the reaction conditions are not mild (reaction temperature $110{ }^{\circ} \mathrm{C}$ ), site-selective fluorination was observed when $\mathbf{2}$ possessing two hydroxy groups was used as a substrate. Fluorine substitution at the hydroxy para to the carbonyl in $\mathbf{2}$ is much faster than that of the ortho-hydroxy, probably due to hydrogen bonding between the ortho-OH and the ester group ${ }^{[14]}$.<smiles>CC1CCCC(=O)CCC/C=C/c2cc(O)cc(O)c2C1=O</smiles>

2

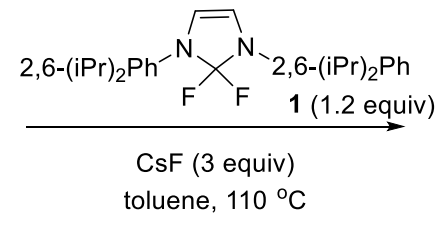

toluene, $110^{\circ} \mathrm{C}$

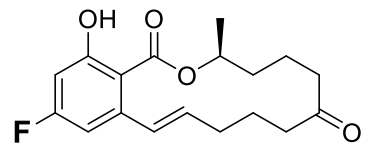

3: $75 \%$

Scheme 3

They also investigated the structure of the intermediate in this reaction. When para-anisol (4) reacted with 1, a condensation reaction took place to give salt 5 in 91\% yield (Scheme 4). Salt 5 reacted with CsF to produce the fluoride $\mathbf{6}$ in $67 \%$ yield. According to the X-ray structure of $\mathbf{5}$, there is a hydrogen bond between one hydrogen atom on the heterocycle and the bifluoride counterion. They speculated that this hydrogen bonding increases the reactivity for fluorinations.

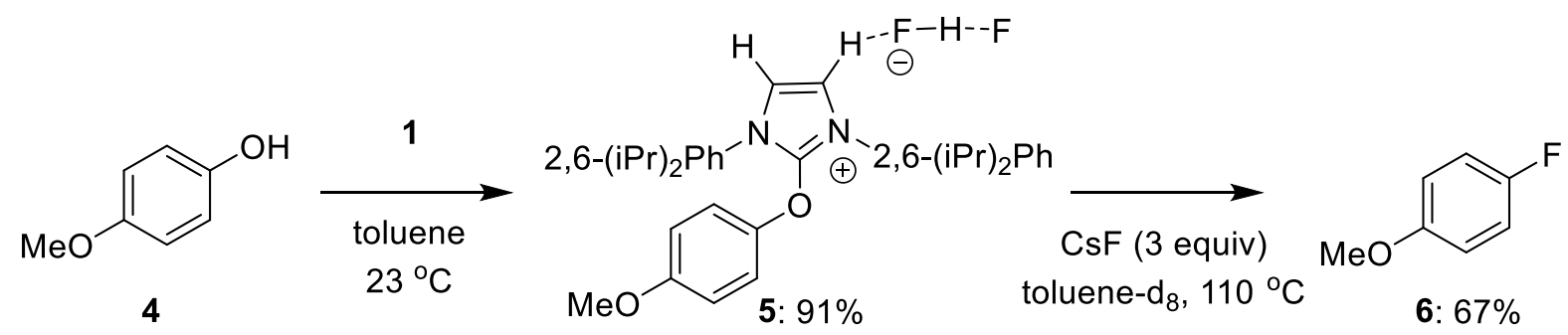

Scheme 4 
A disadvantage of this deoxyfluorination reaction is the use of a stoichiometric amount of PhenoFluor, which generates a lot of waste. However, the operationally simple protocol and high site-selectivity outweighs this drawback. Ritter's group further demonstrated the advantage of PhenoFluor methodology in late-stage deoxyfluorination of alcohols ${ }^{[14 a]}$. In bio-active molecules such as oligomycin $\mathrm{A}$, ivermectin $\mathrm{B}_{\mathrm{la}}$ and everolimus, alcohol groups are located at many positions. Therefore, the late-stage fluorination of such molecules is very difficult without loss of untargeted alcohol groups. The reaction of alcohol, 1, amine and KF enabled accurate site-selective fluorination (Scheme 5). Under the conditions, PhenoFluor 1 can discriminate between different carbinols, despite the presence of multi hydroxy groups in the compounds shown in Scheme 5. Ritter described the selectivity as follows: "(1) primary alcohols are selectively deoxyfluorinated in the presence of secondary and tertiary alcohols. (2) secondary alcohols react significantly slower or not at all when they are $\beta, \beta^{\prime}$-dibranched, unless the secondary alcohol is allylic. (3) tertiary alcohols do not react, unless they are allylic. (4) hydroxy groups engaged in hydrogen bonding are not reactive"(cited from ref 14a). Hu's group also reported site-selective deoxyfluorinations by using 3,3difluoro-1,2-diarylcyclopropenes (CpFluors) ${ }^{[14 b]}$.

\begin{tabular}{|c|c|c|}
\hline \multirow[b]{2}{*}{ Alkyl-OH } & 1 (1.5 equiv) & \multirow[b]{2}{*}{ Alkyl-F } \\
\hline & $\mathrm{EtN}^{\mathrm{i}} \mathrm{Pr}_{2}$ (2 equiv) & \\
\hline & KF (2 equiv) & \\
\hline
\end{tabular}

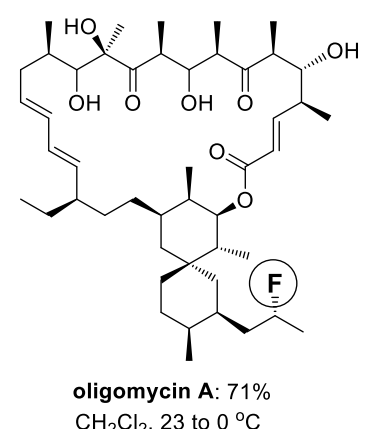

$\mathrm{CH}_{2} \mathrm{Cl}_{2}, 23$ to $0{ }^{\circ} \mathrm{C}$

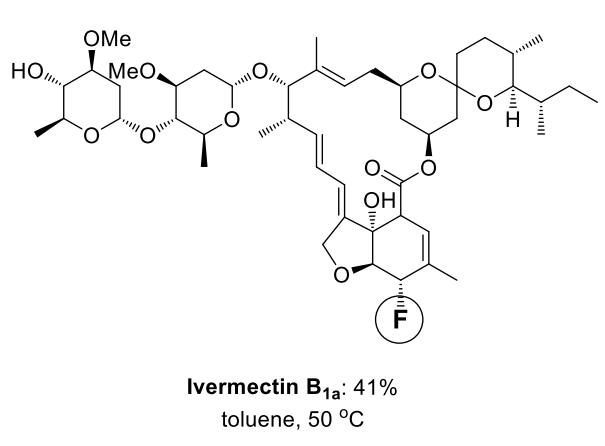

toluene, $50^{\circ} \mathrm{C}$

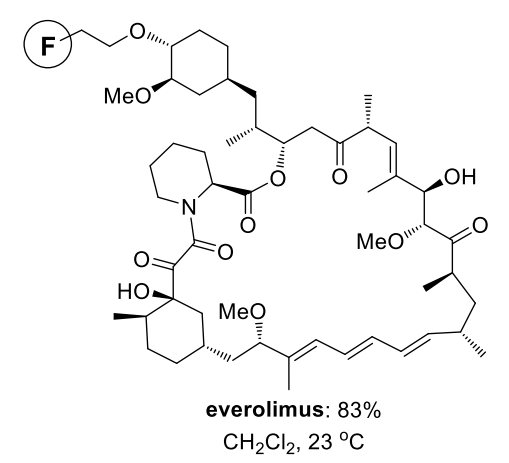

$\mathrm{CH}_{2} \mathrm{Cl}_{2}, 23^{\circ} \mathrm{C}$

Scheme 5

\section{Site-selective fluorination of alkyl halides}

Primary- and secondary-alkyl fluorides can be accessed by conventional nucleophilic fluorination reactions, such as the Finkelstein reaction (Scheme 6) ${ }^{[5,15]}$. Alkyl chlorides, bromides, iodides or triflates can react with fluoride ions to produce alkyl fluorides via nucleophilic substitution. The Finkelstein reaction using an alkali metal fluoride is very convenient and economical, but a major drawback of the reaction is its sensitivity to water. Fluoride ions have a strong tendency to form hydrogen bonds with water molecules which decreases their reactivity. Fluoride ions are also poorly reactive towards tertiaryalkyl halides.

\section{$F$ anion source}

$$
\text { Alkyl-X }
$$$$
\text { Alkyl-F }
$$

$X=$ halogen 
In 2016, Nishikata's group reported that a copper-catalyzed site-selective fluorination of $\alpha$-bromoamides possessing multiple reaction sites 7, such as primary and secondary alkyl-Br bonds, using inexpensive CsF (Scheme 7) ${ }^{[16 a]}$. The reactivities of alkyl halides in nucleophilic fluorination reactions generally follow the order: primary carbon center >secondary carbon center $>$ tertiary carbon center, as observed in an $\mathrm{S}_{\mathrm{N}} 2$ reaction. Interestingly, these copper-catalyzed radical fluorination conditions enabled selective fluorinations at a tertiary-alkyl carbon center to provide fluorinated products $\mathbf{8}$ in good yields. $\mathrm{C}\left(\mathrm{sp}^{2}\right)-\mathrm{Br}$ and $\mathrm{C}\left(\mathrm{sp}^{2}\right)-\mathrm{I}$ bonds are also good reaction sites for catalytic fluorination using metal catalysts, ${ }^{[17]}$ but the products $\mathbf{8 g}$ and $\mathbf{8 h}$ were obtained without loss of the $\mathrm{C}\left(\mathrm{sp}^{2}\right)-\mathrm{Br}$ and $\mathrm{C}\left(\mathrm{sp}^{2}\right)-\mathrm{I}$ bonds. Li's group also reported site-selective fluorinations by using Selectfluor, in which tert-alkyl halogen bonds react exclusively over other alkyl halogen bonds. ${ }^{[16 b]}$

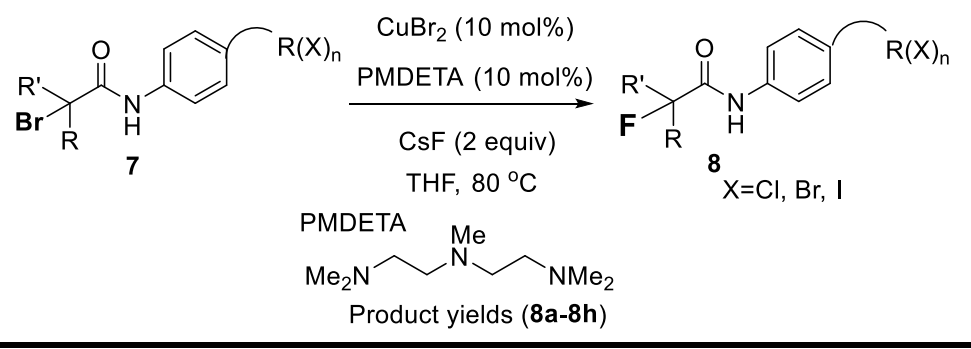<smiles>CC(F)(F)C(=O)Nc1ccc(C(=O)OCCCBr)cc1</smiles><smiles>CC(C)(C)C(=O)Nc1ccc(C(=O)OCC(CBr)(CBr)CBr)cc1</smiles>
$8 c: 74 \%$<smiles>CCCCC(F)(CC)C(=O)Nc1ccc(C(=O)OCCCCl)cc1</smiles><smiles>CC(C)(C)OC(=O)c1ccc(C(=O)OCc2ccc(Br)cc2)cc1</smiles><smiles>CC(C)(C)C(=O)Nc1ccc(C(=O)OCC(Br)CBr)cc1</smiles><smiles>CCC(=O)Nc1ccc(C(=O)N2CCC(Br)CC2)cc1</smiles><smiles>C=C(Br)COC(=O)c1ccc(NC(=O)C(C)(C)C)cc1</smiles>
8f: $63 \%$<smiles>CC(C)(F)C(=O)Nc1ccc(C(=O)OCc2ccc(I)cc2)cc1</smiles>

Scheme 7

Control experiments revealed that in situ generated $\mathrm{CuF}_{2}$ is the key fluorinating reagent that reacts with tertiary alkyl radicals generated by the reaction between an $\alpha$-bromocarbonyl compound and a copper(I) salt (Scheme 8 ). The reaction discriminates between different reactive alkyl-X bonds, producing the corresponding monofluorinated product $\mathbf{8}$ selectively.

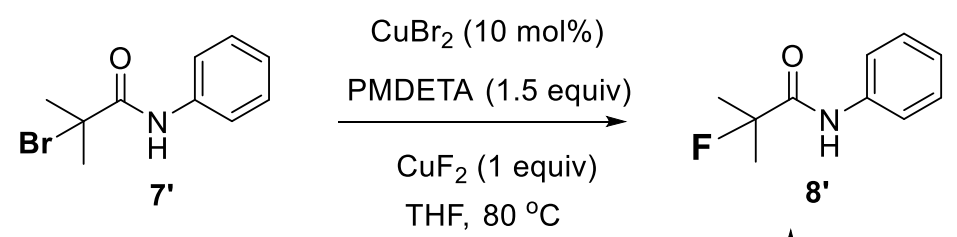

Scheme 8

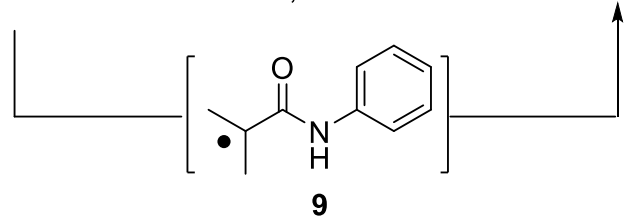


Allylic fluorides are important fragment in a range of pharmaceuticals, and agrochemicals ${ }^{[18]}$. Those allylic fluorides can be synthesized from the reaction of allylic electrophiles with fluoride anions, but this poses a problem in terms of site-selectivity (regioselectivity), in which either a linear or branched allylic fluoride can be generated (Scheme 9).

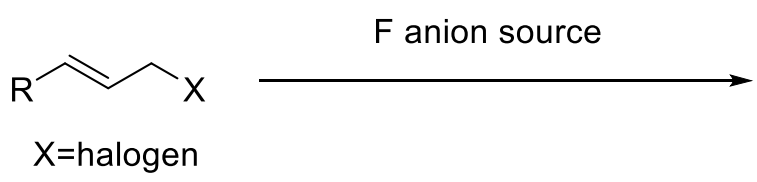

Scheme 9

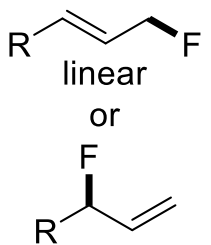

branched

In Pd-catalyzed allylic fluorinations, branched-selective reaction is useful for enantioselective fluorination. Doyle's group reported the $\mathrm{Pd}(0)$-catalyzed allylic fluorination of linear allylic chlorides $\mathbf{1 0}$ to produce branched allylic fluorides $\mathbf{1 1}$ (Scheme 10) ${ }^{[19]}$. Aliphatic allylic chlorides resulted in good branched selectivities and high enantioselectivities. The naphthylsubstituted Trost ligand plays an important role for controlling the branched selectivity. However, cinnamyl chloride and its derivatives provided low regioselectivity under the best conditions.

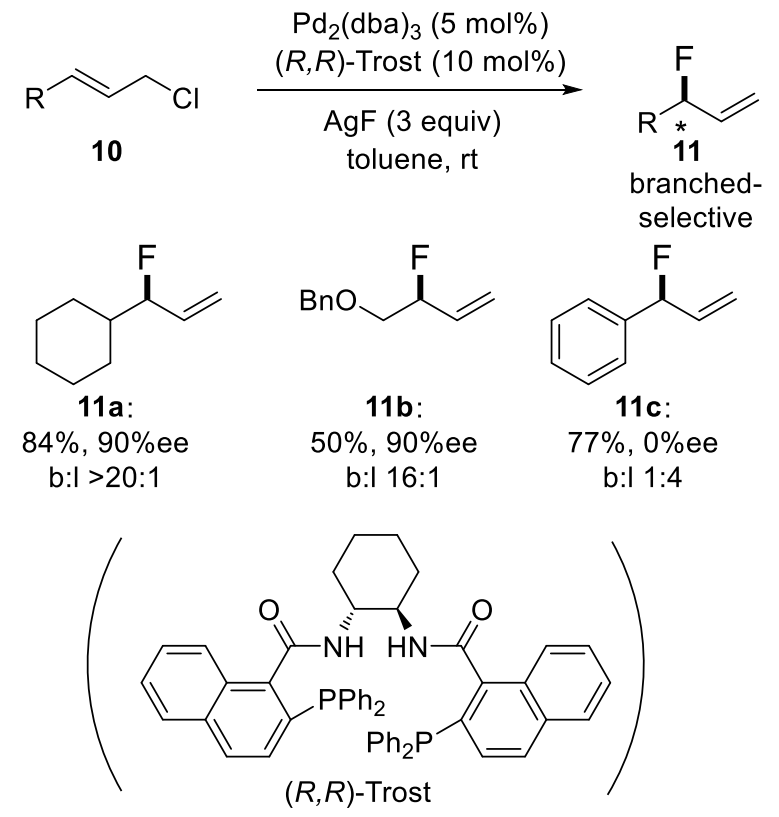

Scheme 10

The synthesis of branched allylic fluorides from cinnamyl derivatives is very difficult because of the conjugation between the aromatic ring and the alkene. However, linear-selective allylic fluorinations $\mathbf{1 3}$ can be achieved using cinnamyl caboxylate derivatives 12 in the presence of a palladium catalyst and TBAF tert-butyl alcohol complex [TBAF $\left.(t \mathrm{BuOH})_{4}\right]$, which has low hygroscopicity and basicity (Scheme 11) ${ }^{[20]}$. 


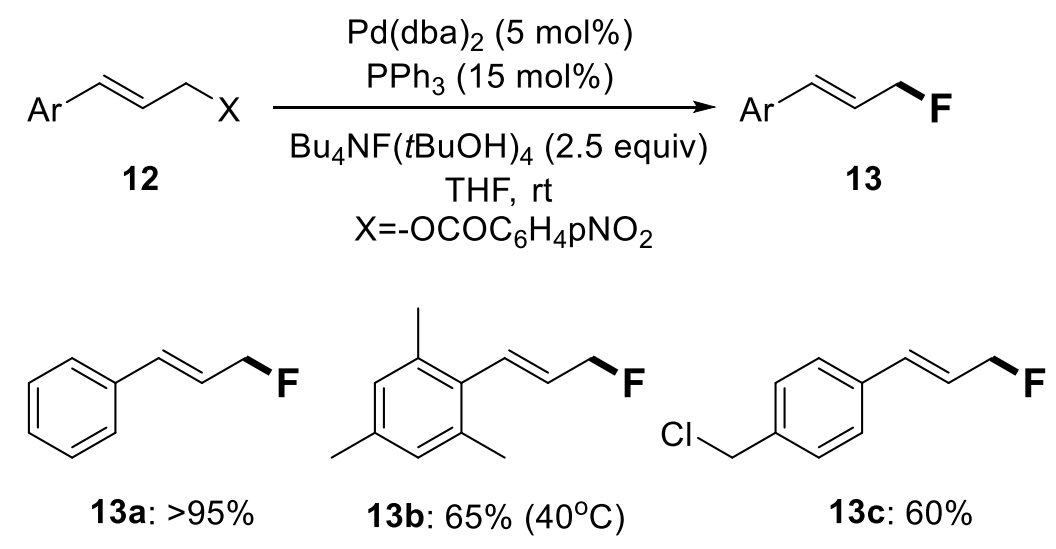

Scheme 11

Nguyen's group reported that allylic trichloroacetimidates $\mathbf{1 4}$ undergo site-selective fluorination in the presence of an iridium catalyst (Scheme 12) ${ }^{[21]}$. As above (Scheme 10), aliphatic allylic electrophiles gave excellent branched-selectivity. They also tested various Lewis acid catalysts, such as $\mathrm{Zn}(\mathrm{OTf})_{2}, \mathrm{Cu}(\mathrm{OTf})_{2}$, and palladium catalysts, but the desired product 15 was not obtained. According to their control experiments, the reaction may occur through an $\mathrm{S}_{\mathrm{N}} 1$ mechanism, but the details were not clear. In the case of copper fluoride-mediated allylic fluorinations of linear allylic chloride 16, the linear-product 17 was obtained (Scheme 13) ${ }^{[22]}$. This fluorination reaction is expected to be an $\mathrm{S}_{\mathrm{N}}$ 2-like reaction (Finkelstein reaction) but other fluorides, such as $\mathrm{CsF}$ and $\mathrm{LiF}$, were not reactive.
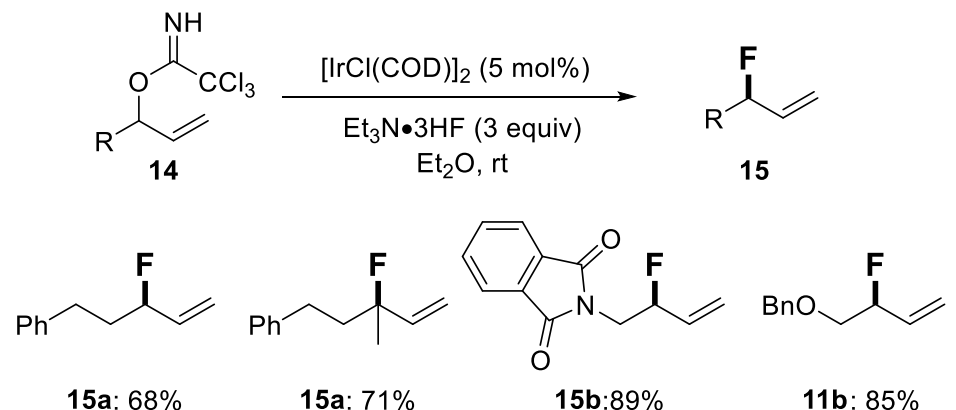

Scheme 12

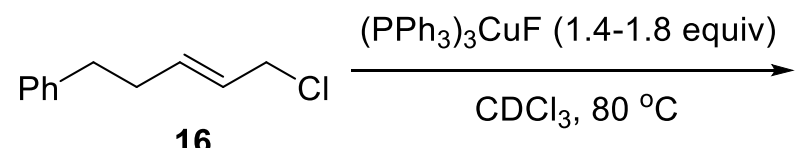

16

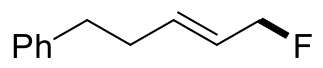

17: $53 \%$

Scheme 13

An interesting site-selective allylic fluorination reaction can be achieved using a carbonyl group as a directing group to control the regioselectivity (Scheme 14) ${ }^{[23]}$. The fluorination reactions occurred directly at the $\mathrm{C}-\mathrm{Br}$ bond ( $\alpha$ substitution not $\gamma$ ) to produce allylic fluorides 19. On the other hand, the reaction of 18a provided $\mathrm{Y}^{-}$fluorinated product $19 \mathrm{a}$ in $78 \%$ yield (Scheme 15). To explain this site selectivity, Liu suggested that both reductive elimination and $\mathrm{S}_{\mathrm{N}} 2$-type attack of the allylic $\mathrm{Cu}^{\mathrm{III}}$ complex are possible. The coordination of oxygen to the copper is important not only for site-selectivity but also for reactivity; when 2-bromo-3-dodecene was used as a substrate, the fluorination reaction did not occur at all. 
$\overbrace{R^{\prime}}^{B r}$

18

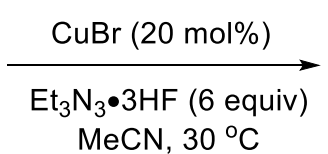

$\mathrm{MeCN}, 30^{\circ} \mathrm{C}$
$\overbrace{19}^{\mathrm{R}_{\mathrm{R}^{\prime}}}$<smiles>[3H]N1CCCC1/C=C/C([13CH3])F</smiles>

19a: $82 \%$ $\mathrm{dr}=4: 1$<smiles>O=C1c2ccccc2C(=O)N1C/C=C/C(F)Cc1ccccc1</smiles>

19b: $45 \%$<smiles>CCOC(=O)CC=CC(C)F</smiles>

19c: $49 \%$

Scheme 14<smiles>[M]C=CC(Br)C1CCCN1[AsH3]</smiles>

$18 a$

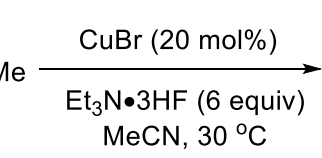
$\mathrm{MeCN}, 30^{\circ} \mathrm{C}$

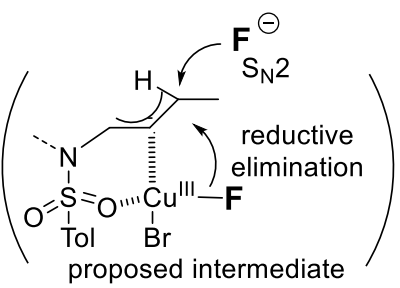<smiles></smiles>

$d r=5: 1$

Scheme 15

\section{Site-selective fluorination of $\mathrm{C}-\mathrm{H}$ bonds Alkane $\mathrm{C}-\mathrm{H}$ bonds}

One of the most attractive and ideal functional groups for fluorination reaction is a $\mathrm{C}-\mathrm{H}$ bond. Since a molecule generally has various $\mathrm{C}-\mathrm{H}$ bonds including aromatic, aliphatic $\left(1^{\circ}, 2^{\circ}\right.$ or $\left.3^{\circ}\right)$, allylic and benzylic $\mathrm{C}-\mathrm{H}$ bonds, it can be very difficult to distinguish the target $\mathrm{C}-\mathrm{H}$ bond using reactive fluorinating reagents (Figure 1) ${ }^{[24]}$.

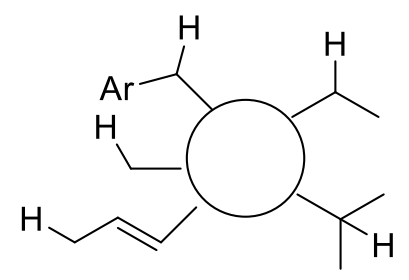

Figure 1

One of the best $\mathrm{C}-\mathrm{H}$ fluorination methodologies for unactivated $\mathrm{C}-\mathrm{H}$ bonds is a photo catalytic reaction which involves a photo excited intermediate. The reactive excited intermediate can undergo hydrogen atom abstraction from aliphatic substrates $^{[25]}$. The resulting radical intermediate reacts with a fluorinating reagent to produce the corresponding fluoroalkane. This reaction provides direct access to fluorinated alkanes but the yields are generally not high. The site selectivities in the 
reaction are generally dependent on the stability of the generated radicals $\left(3^{\circ}>2^{\circ}>>1^{\circ}\right)$.

Tan's group discovered an anthraquinone (AQN) catalyzed C-H fluorination reaction in the presence of Selectfluor (Scheme 16) ${ }^{[26]}$. In this reaction, a cationic N-radical from Selectfluor activates AQN (triplet AQN) under photo irradiation to produce active fluorinated AQN (AQN+F) which abstracts a hydrogen atom from alkane $\mathbf{2 0}$ to generate a carbon centered radical. The generated radical reacts with $\mathrm{AQN}+\mathrm{F}$ to give the corresponding fluorinated alkane 21. As this is a radical reaction, the reactivity and selectivity depend on the stability of the intermediate radicals. When 21e possessing $3^{\circ}$ and $2^{\circ}$ alkyl moieties was used, the fluorination reaction selectively occurred at the $3^{\circ}$ carbon. On the other hand, the site selectivity in the formation of fluorides 21a-21d was not explained.

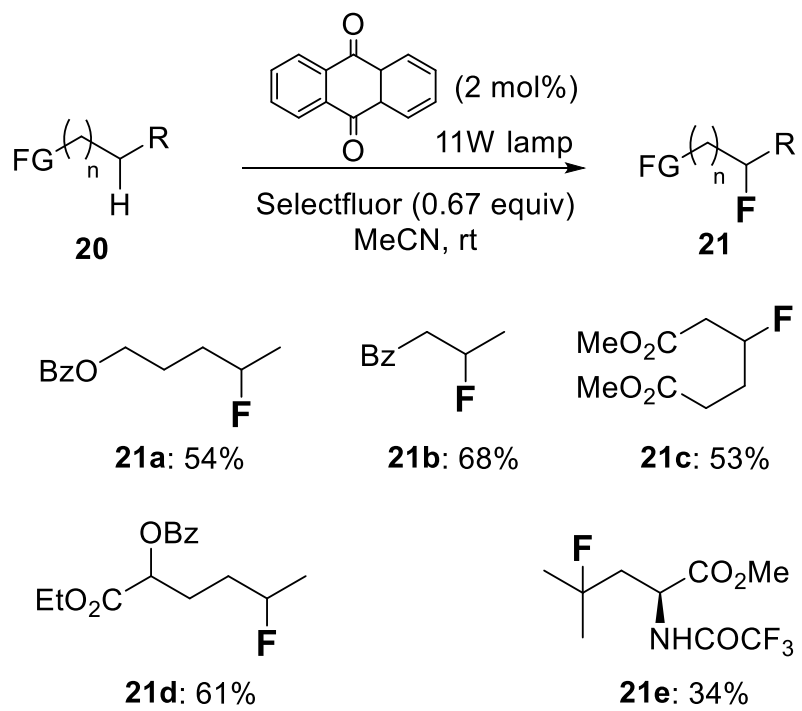

Scheme 16

Acetophenone $(\mathrm{MeCOPh})$ is also good catalyst for alkane $\mathrm{C}-\mathrm{H}$ fluorination (Scheme 17) ${ }^{[27]}$. Fluorination reactions in the presence of Selectfluor, and $\mathrm{MeCOPh}$ under photo irradiation provided site-selective fluorination for $3^{\circ}$ over $2^{\circ}$ carbons. As above (Scheme 16), the reaction depends on the stability of the intermediate carbon radicals and $3^{\circ}$ radicals are more readily formed than $2^{\circ}$ radicals.

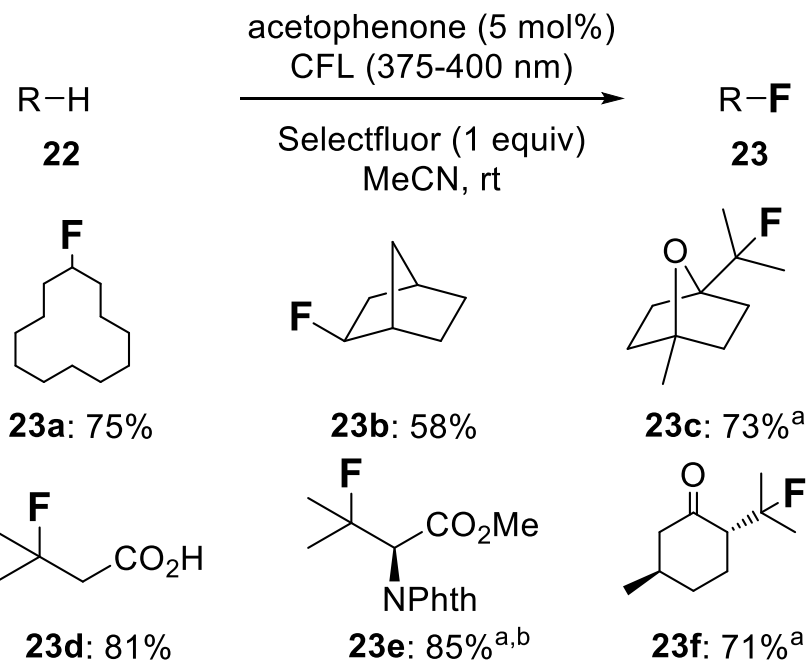

${ }^{a} 1.5$ equiv Selectfluor. ${ }^{b} 20$ mol\% acetophenone

Scheme 17 
Photo-excited decatungstate $\left(\mathrm{W}_{10} \mathrm{O}_{32}{ }^{4-}\right)$ is also a good catalyst for unactivated alkane $\mathrm{C}-\mathrm{H}$ fluorination in the presence of NFSI under photo irradiation (Scheme 18) ${ }^{[28]}$. Although substrates possessing $2^{\circ} \mathrm{C}-\mathrm{H}$ did not undergo site selective fluorination, substrates possessing $3^{\circ} \mathrm{C}-\mathrm{H}$ provided excellent site selectivities (25a-25c).

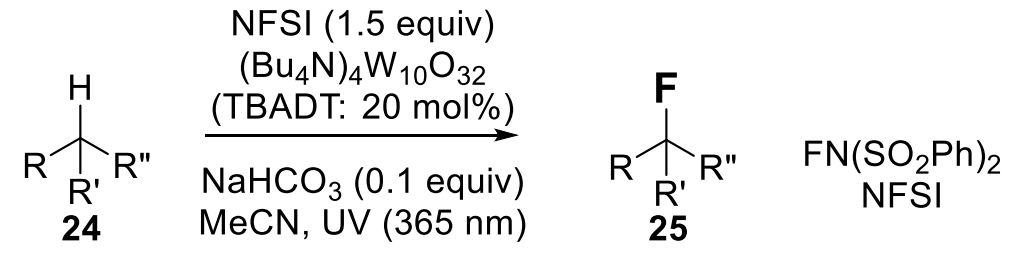<smiles>CCOCCC(C)(C)F</smiles>

25a:

$45 \%$<smiles>CCOC(=O)CCC(C)(C)F</smiles>

25b: $40 \%$<smiles>CCOC(=O)C(N)C(C)(C)F</smiles>

25c: $56 \%$

Scheme 18

A carbonyl group is often useful for a directed fluorination reaction. Lectka's group reported the late-stage fluorination of polycyclic terpenoid derivatives 26 possessing an enone structure (Scheme 19) ${ }^{[29]}$. Under photo irradiation, triplet excited enone abstracts a $Y^{-h}$ hydrogen atom to generate a radical intermediate. The resulting carbon-centered radical is susceptible to fluorination with Selectfluor and produces the fluorinated terpenoid 27 site selectively.

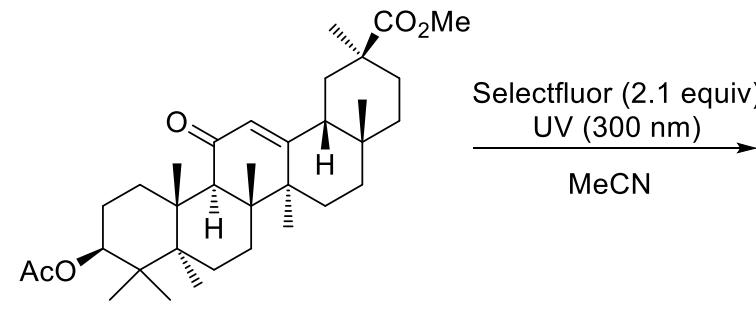

26

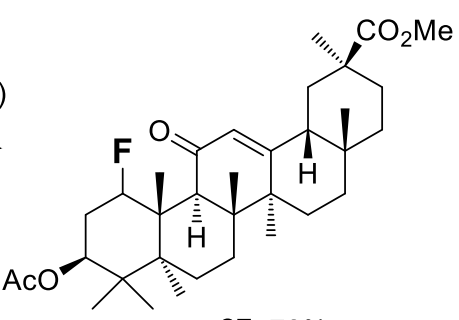

27: $72 \%$

$(\alpha: \beta=4.8: 1)$

Scheme 19

Tang's group reported a site-selective fluorination using Selectfluor II in the presence of $\mathrm{K}_{2} \mathrm{~S}_{2} \mathrm{O}_{8}$ (Scheme 20) ${ }^{[30]}$. In this reaction, Selectfluor or NFSI were not effective at all, but Slectfluor II was found to be a good fluorinating reagent. Both $3^{\circ}$ and $2^{\circ} \mathrm{C}-\mathrm{H}$ bonds underwent single and site-selective fluorination to produce the corresponding fluoroalkanes (29a-29f). $3^{\circ}$ $\mathrm{C}-\mathrm{H}$ bonds were found to be react much faster than $2^{\circ} \mathrm{C}-\mathrm{H}$ bonds because of the radical pathway. This method can be applicable to late-stage fluorination of natural products and derivatives. For example, sclareolide, and a diterpene derived from gibberellic acid, proceeded to form the fluorinated products $(\mathbf{2 9 g}$ and $\mathbf{2 9 h})$ with excellent site selectivity. 


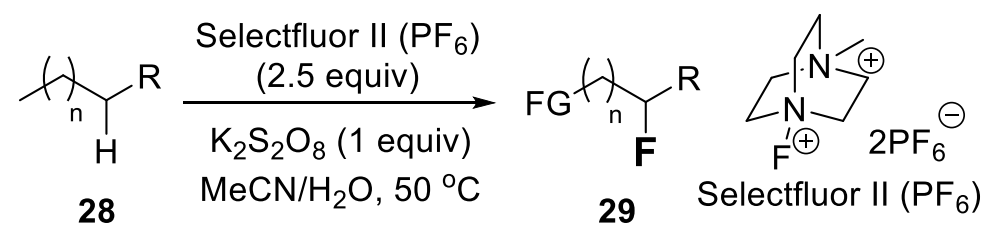<smiles>[R6]OCCC(C)F</smiles>

29a: $65 \%$

( 2 equiv $\mathrm{K}_{2} \mathrm{~S}_{2} \mathrm{O}_{8}$ )<smiles>CC(CCC(C)(C)O)OC(C)(C)C</smiles>

29d: $65 \%$<smiles>C[C@@H]1CC(F)C[C@@]2(C)[C@H]1CC[C@]1(C)OC(=O)C[C@@H]12</smiles>

29g: $69 \%$<smiles>CC(C)(C)COC(=O)O</smiles>

29b: $98 \%$<smiles>CC(CCCC(C)(C)F)[N+](=O)[O-]</smiles>

29e: $63 \%$<smiles>CC(C)(F)CCO[R6](=O)c1ccccc1</smiles>

29c: $82 \%$<smiles>FC1CCCCC1</smiles>

29f: $63 \%$

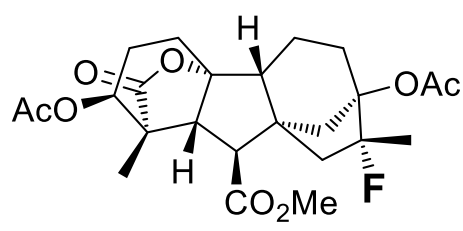

29h: $42 \%$

Scheme 20

Palladium-catalyzed fluorination reactions offer another option for site-selective fluorinations. Xu and Ge's group independently reported directed $\mathrm{C}-\mathrm{H}$ activation for fluorination in the presence of a palladium catalyst and NFSI or Selectfluor (Scheme 21) ${ }^{[31 a, b]}$. The reaction conditions (A and B) differ slightly, but the same five-membered palladacycle intermediate was proposed for both $\mathrm{C}-\mathrm{H}$ fluorinations although different directing groups were employed [(2-(pyridine-2yl)isopropyl and quinoline]. The fluorinations occurred at the $\beta$-carbon with respect to the carbonyl group to generate $\beta$ fluorinated products (31a-31c) exclusively. Yu and Shi's group also reported a directed C-H fluorination reaction via a similar intermediate $^{[31 c, d]}$.<smiles>[R]CC(=O)NC([R])[2H]</smiles>

30<smiles>[R]NC(=O)CC(F)CC</smiles>

31a: $60 \%(A)$ $81 \%(B)$

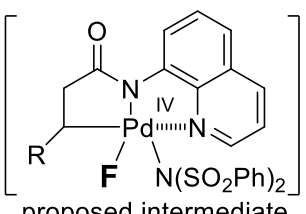
proposed intermediate
Conditions ( $A$ or $B$ )<smiles>[R]NC(=O)CC(F)C1CCCCC1</smiles>

31b: $43 \%(A, n=1)$

\begin{tabular}{|c|c|}
\hline Conditions A & Conditions B \\
\hline $\mathrm{Pd}(\mathrm{OAc})_{2}(15 \mathrm{~mol} \%)$ & $\mathrm{Pd}(\mathrm{OAc})_{2}(10 \mathrm{~mol} \%)$ \\
\hline $\mathrm{FN}\left(\mathrm{SO}_{2} \mathrm{Ph}\right)_{2}$ (NFSI: 2 equiv) & Selectfluor (2.5 equiv) \\
\hline $\mathrm{Ag}_{2} \mathrm{O}$ (1 equiv) & $\mathrm{Ag}_{2} \mathrm{CO}_{3}$ (2 equiv) \\
\hline $\mathrm{PivOH}$ (1 equiv) & $\mathrm{Fe}(\mathrm{OAc})_{2}(0.75$ equiv $)$ \\
\hline chlorobenzene, $120^{\circ} \mathrm{C}$ & $\mathrm{MeCN},\left(\mathrm{CH}_{2} \mathrm{Cl}\right)_{2}, 150^{\circ} \mathrm{C}$, Air \\
\hline
\end{tabular}

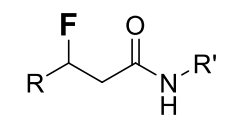

31<smiles>[R]NC(=O)CC(F)Cc1ccccc1</smiles>

31c: $50 \%(A)$

Scheme 21 


\section{Allylic C-H bonds}

As described above, $\mathrm{C}-\mathrm{H}$ fluorinations of alkyl $3^{\circ}$ and $2^{\circ} \mathrm{C}-\mathrm{H}$ bonds can be achieved by suitable choice of conditions. Allylic $\mathrm{C}-\mathrm{H}$ bonds are potentially one of the best fluorination targets. The main difficulty in site-selective allylic $\mathrm{C}-\mathrm{H}$ fluorination is controlling the linear/branched selectivity (Scheme 22). The chemistry of allylic $\mathrm{C}-\mathrm{H}$ fluorination is premature but there are two good examples.

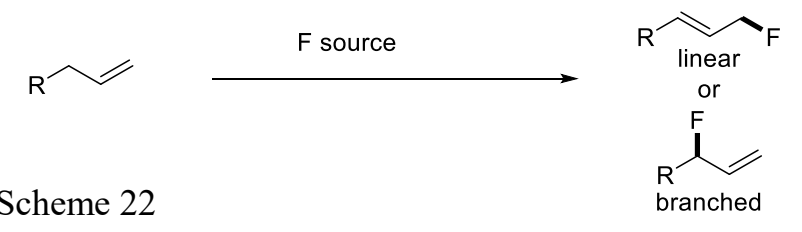

Doyle's group has reported palladium/chromium-catalyzed allylic $\mathrm{C}-\mathrm{H}$ fluorinations with ammonium fluoride as a fluorinating reagent (Scheme 23) ${ }^{[32]}$. The electrophilic $\mathrm{Pd}^{\mathrm{II}}$-sulfoxide catalyst system ${ }^{[33]}$ smoothly activates an allylic $\mathrm{C}-\mathrm{H}$ bond of 32 to undergo site-selective fluorination with moderate to good branched-selectivities (33a-33c). This protocol can be applied to the late-stage fluorination of steroid derivatives to produce $\mathbf{3 3 d}$.

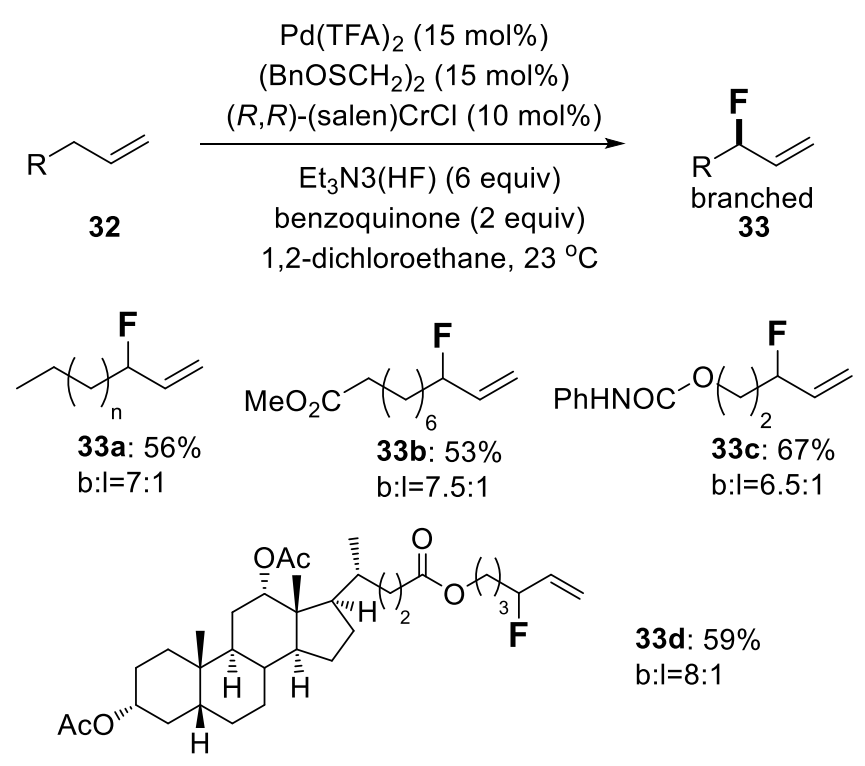

Scheme 23

Lectka's group also reported allylic $\mathrm{C}-\mathrm{H}$ fluorinations with excellent site selectivities ${ }^{[34]}$. A mixture of silver and selenium salts in the presence of $\mathrm{NfPyBF}_{4}$ enabled fluorination of alkenes $\mathbf{3 4}$ to produce various allylic fluorides $\mathbf{3 5}$. The reaction might involve either a carbocation or a radical but the observed site selectivity did not provide a means to distinguish between these possibilities.

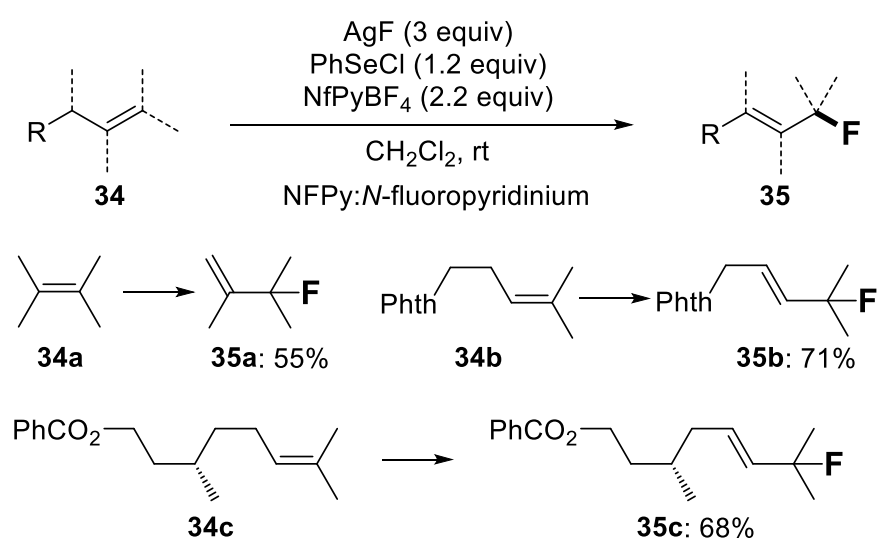

Scheme 24 


\section{Benzylic C-H bonds}

There are some reports on benzylic $\mathrm{C}-\mathrm{H}$ fluorinations but most of the reactions are not site-selective ${ }^{[35]}$. Since the benzylic $\mathrm{C}-\mathrm{H}$ fluorinations involve a radical mechanism, it is very difficult to achieve high selectivity. Britton's group reported site selective fluorinations of pyridine derivatives 36 in the presence of NFSI (Scheme 25) ${ }^{[36]}$. When pyridine derivatives 36 were used under their optimized conditions including NFSI and $\mathrm{Li}_{2} \mathrm{CO}_{3}$, selective fluorinated products 37 were obtained. Those site selectivities could be explained by the proposed intermediate, which is generated via formation of an $N$-sulfonyl pyridinium salt.

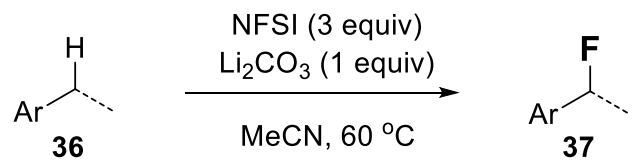<smiles>N#Cc1cncc2c1C(F)CC2</smiles>

37a: $60 \%$<smiles>Fc1cc(C(F)(F)F)ccc1-c1cncc2c1C(F)CC2</smiles>

37b: $78 \%$<smiles>FC1CCCc2cnccc21</smiles>

37c: $68 \%$<smiles>Cc1ccc(C(C)C)cc1</smiles>

Scheme 25

They also demonstrated the site-selective late-stage $\mathrm{C}-\mathrm{H}$ fluorination of ibuprofen derivative $\mathbf{3 8}$ (Scheme 26). Simply heating 38 with NFSI provided pyridylic fluoride $\mathbf{3 8 a}$ in 54\% yield. The reaction of $\mathbf{3 8}$ with LDA produced an anion at the carbonyl $\alpha$-position, which reacted with NFSI to produce $\alpha$-fluoroester $\mathbf{3 8 b}$ in $63 \%$ yield. Photocatalytic decatungstate reaction conditions led to benzylic fluorination to produce $\mathbf{3 8} \mathbf{c}^{[28 a]}$.

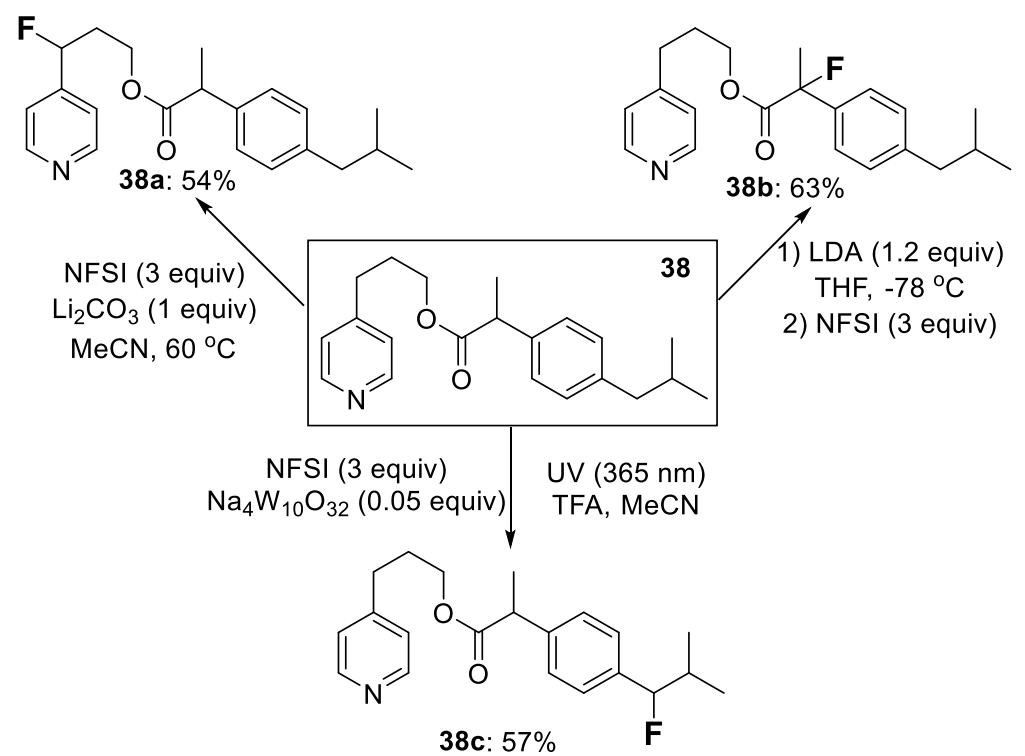

Scheme 26 
Groves's group reported manganese catalyzed site-selective fluorinations in the presence of trimethylamine trihydrofluoride via a radical pathway (Scheme 27) ${ }^{[37]}$. In situ generated manganese oxide formed from the reaction of $\mathrm{MnCl}$ and $\mathrm{PhIO}$ smoothly provided a benzylic radical from the benzylic $\mathrm{C}-\mathrm{H}$ bond of $\mathbf{3 9}$, which reacted with the fluorinating reagent to produce the corresponding site-selective fluorinated products $\mathbf{4 0 .}$

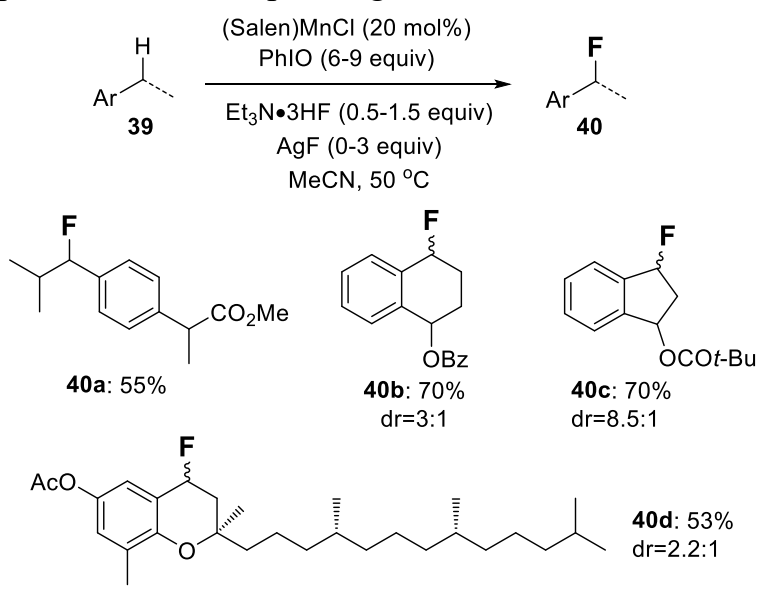

Scheme 27

\section{Aryl C-H bonds}

The formation of aryl-fluorine bonds ${ }^{[38]}$ has often proved even more challenging than the synthesis of alkyl-fluorine bonds, as nucleophilic fluorination reactions do not usually proceed effectively unless the aromatic ring is very electron deficient. Nevertheless, as noted above, recent progress has been made on the direct fluorination of phenols using a novel deoxyfluorinating agent ${ }^{[13]}$. The majority of recent work on the synthesis of aromatic fluorides, however, has focused on the development of novel transition-metal mediated fluorination reactions. Broadly speaking, these reactions fall into three different categories: 1) metal-mediated nucleophilic fluorination of aryl halides or triflates ${ }^{[39]}$; 2) metal-mediated fluorination of organoboron, organostannane or organosilane derivatives ${ }^{[40]}$; and 3) metal-mediated direct fluorination of C-H bonds. In the first two cases, the site selectivity is controlled by the location of the functional group already present (e.g. aryl halide, aryl trifluoroborate), so these methods will not be discussed in detail here. In the third case, the site selectivity of the C-H functionalisation must be controlled by the transition-metal species used to mediate the reaction.

In 2006, Sanford and co-workers reported the first Pd-catalysed fluorination of C-H bonds, including some arene examples, using nitrogen-containing directing groups ${ }^{[41]}$. Recent work in the area has led to the development of milder methods for C$\mathrm{H}$ fluorination of a wider range of aromatic systems. For example, $\mathrm{Xu}$ and co-workers found a Pd-catalysed $\mathrm{C}-\mathrm{H}$ fluorination reaction was significantly accelerated by the addition of nitrate ions (Scheme 28$)^{[42]}$. Their new protocol enabled the Pdcatalysed fluorination of aromatic $\mathrm{C}-\mathrm{H}$ bonds adjacent to oximes (41) to take place at temperatures of $25-40{ }^{\circ} \mathrm{C}$. The same group also developed a method for site-selective $\mathrm{C}-\mathrm{H}$ fluorination of phenol derivatives using a removable pyridyl directing group ${ }^{[43]}$, but harsher reaction conditions were required in this case. 
$\underbrace{N_{N}}_{41}$<smiles>CON=C(C)c1cc(C(F)(F)F)ccc1F</smiles>

42b: $80 \%$<smiles>CON=C1CCCc2cccc(F)c21</smiles>

42c: $87 \%$

Scheme 28

Further progress has been made in the identification of novel directing groups for aromatic $\mathrm{C}-\mathrm{H}$ fluorination. Yu and coworkers showed that electron-deficient aromatic benzamides (43) could be used to achieve selective C-H fluorination using a palladium catalyst in combination with an $N$-fluoropyridinium salt (Scheme 29) ${ }^{[4]}$. Addition of a small quantity of NMP to the reaction was found to result in an increase in the reaction yield. The amide group could be cleaved under basic conditions to provide access to the corresponding ortho-fluorobenzoic acids (44a-c).<smiles>O=C(N[Al])c1cc#[R]cc1</smiles>
$\mathrm{Ar}=p-\mathrm{CF}_{3} \mathrm{C}_{6} \mathrm{H}_{4}$<smiles>O=C(N[Al])c1ccc(Br)cc1F</smiles>

44a: $69 \%$

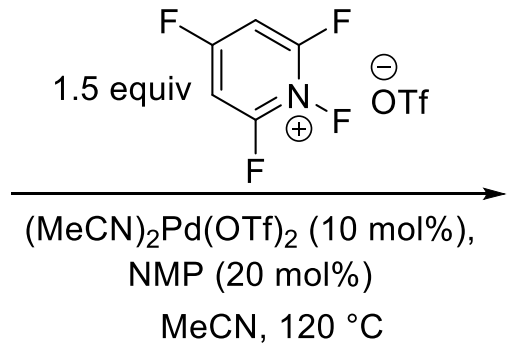<smiles>O=C(N[Al])c1cc[R]cc1F</smiles>

$\mathrm{MeCN}, 120^{\circ} \mathrm{C}$<smiles>O=C(N[Ga])c1c(F)cccc1C(F)(F)F</smiles>

44b: $70 \%$<smiles>N#Cc1ccc(C(=O)N[Al])c(F)c1</smiles>

44c: $62 \%$

Scheme 29

Zhao and co-workers developed a method for regioselective $\mathrm{C}-\mathrm{H}$ fluorination of benzylamine derivatives (45), using an oxalyl amide directing group (Scheme 30$)^{[45]}$. The reaction takes place at moderate temperature using only 5 mol\% palladium(II) acetate and NFSI as the fluorine source. The reaction for one example was performed on a gram scale, with comparable yield, and the directing group could be removed via basic hydrolysis.<smiles>[R]C(NC(=O)C(=O)NC(=O)c1cc#[R]cc1)c1ccccc1</smiles>

$\mathrm{Pd}(\mathrm{OAc})_{2}(5 \mathrm{~mol} \%), \mathrm{NFSI}(3$ equiv)<smiles>Cc1cc(F)c(CNC(=O)C(=O)N=C2CCCCC2)cc1C</smiles>

${ }^{t} \mathrm{AmOH}, 80^{\circ} \mathrm{C}$<smiles>[R6]NC(=O)C(=O)NC([R])c1ccc[R1]c1F</smiles>

46a: $95 \%$<smiles>O=C(NCc1ccc(Br)cc1F)C(=O)N1CCCCC1</smiles><smiles>C=Cc1ccc(CNC(=O)C(=O)N(C(=O)OC(C)(C)C)C(=O)c2ccccc2)c(F)c1</smiles>

Scheme 30 
Daugulis and co-workers reported a copper-catalysed aryl C-H fluorination, using $\mathrm{AgF}$ as the fluorine source, with $\mathrm{N}$ methylmorpholine- $N$-oxide as a stoichiometric oxidant (Scheme 31) ${ }^{[46]}$. The reaction can be applied to amide derivatives of benzoic acids (47), and either mono or difluorination could be achieved depending on the choice of reaction conditions. The latter reaction was also applied to benzylamine amide derivatives. The main drawback of this method is the requirement for a large excess of $\mathrm{AgF}$ as the fluoride source.<smiles>[Z7][R]1ccc(C(=O)Nc2cccc3cccnc23)cc1</smiles>

\section{Cul (10-25 mol\%), AgF (3-4 equiv)} $\mathrm{NMO}\left(4.5-5\right.$ equiv), DMF, $50-125^{\circ} \mathrm{C}$

47<smiles>O=C(Nc1cccc2cccnc12)c1ccc(C(F)(F)F)cc1F</smiles>

48a: $71 \%$<smiles>O=C(Nc1cccc2cccnc12)c1ccncc1F</smiles>

48b: $62 \%$<smiles>[R]c1ccc(F)c(C(=O)Nc2cccc3cccnc23)c1</smiles>

Scheme 31

A remarkable site-selective direct fluorination of pyridines and related heterocycles (49) using $\mathrm{AgF}_{2}$ was reported by Hartwig ${ }^{[47]}$. The reaction leads exclusively to fluorination at the 2-position of pyridines, and a nucleophilic addition/oxidation pathway was proposed. The reaction could even be applied directly to the fluorination of pyridine-containing pharmaceuticals. The main drawback is the requirement for a large excess of the silver salt.

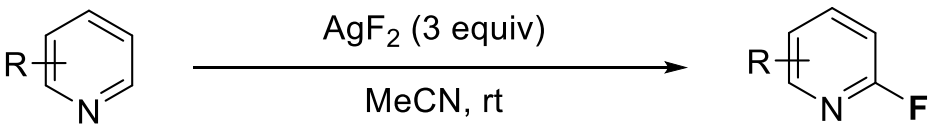

49<smiles>Cc1cc(Cl)cc(F)n1</smiles>

50a: $75 \%$<smiles>CCOC(=O)c1cccc(F)n1</smiles>

50b: $67 \%$<smiles>Cn1c(=O)n(C2CCN(C(=O)OCc3ccccc3)CC2)c2ccc(F)nc21</smiles>

50c: $75 \%$<smiles>Cn1c(F)c(C(=O)Nc2cccc3cccnc23)c2ccccc21</smiles>

48c: $54 \%$

Scheme 32

\section{Conclusions and perspectives}

The present reactions summarize and highlight recent progress in site-selective fluorination reactions using electrophilic, nucleophilic, and radical pathways in the presence/absence of a metal catalyst or photo catalyst. Site-selective fluorinations are very attractive for late-stage synthesis of a complex fluorinated molecules. Although there are many reports of fluorination methods, control of the site-selectivity remains a significant challenge, especially in the direct fluorination of C-H bonds. The methodology summarised here shows how progress has been made in terms of controlling the site selectivity of fluorination, but most reactions are still very substrate dependent and give low to moderate yields. These are problems that will need to be solved in the future.

\section{Acknowledgement}

We warmly thank the program to disseminate tenure tracking system, MEXT, Japan, Grant-in-Aid for Challenging Exploratory Research Grant No:16K13995 and the UBE foundation. 


\section{References}

1 Müller, K.; Faeh, C.; Diederich, F. Science 2007, 317, 1881.

2 Wong, D. T.; Bymaster, F. P.; Engleman, E. A. Life Sci. 1995, 57, 411.

3 Roth, B. D. in Progress in Medicinal Chemistry, vol. 40, F. D. King, A. W. Oxford, Eds. (Elsevier, Amsterdam, 2002), pp. 1-22.

4 Drlica, K.; Malik, M. Curr. Top. Med. Chem. 2003, 3, 249.

5 Kirsch, P. in Modern fluoroorganic chemistry, Wiley-VCH, Weinheim, 2004.

6 Champagne, P. A.; Desroches, J.; Hamel, J.-D.; Vandamme, M.; Paquin, J.-F. Chem. Rev. 2015, 115, 9073.

7 Radical fluorinations via Hunsdieker type reaction: (a) Patel, N. P.; Flowers II, R. A. J. Org. Chem. 2015, 80, 5834; (b) Yin, F.; Wang, Z.; Li, Z.; Li, C. J. Am. Chem. Soc. 2012, 134, 10401; (c) Leung, J. C. T.; Chatalova-Sazepin, C.; West, J. G.; Rueda-Becerril, M.; Paquin, J.-F.; Sammis,

G. M. Angew. Chem., Int. Ed. 2012, 51, 10804; (d) Ventre, S.; Petronijevic, F. R.; MacMillan, D. W. C. J. Am. Chem. Soc. 2015, 137, 5654; (e) Rueda-Becerril, M.; Mahé, O.; Drouin, M.; Majewski, M. B.; West, J. G.; Wolf, M. O.; Sammis, G. M.; Paquin, J.-F. J. Am. Chem. Soc. 2014, 137, 2637; (f) Rueda- Becerril, M.; Sazepin, C. C.; Leung, J. C. T.; Okbinoglu, T.; Kennepohl, P.; Paquin, J.-F.; Sammis, G. M. J. Am. Chem. Soc. 2012, $134,4026$.

8 See other radical fluorinations: (a) Li, Z.; Wang, Z.; Zhu, L.; Tan, X.; Li, C. J. Am. Chem. Soc. 2014, 136, 16439; (b) Patrick, T. B.; Khazaeli, S.; Nadji, S.; Hering-Smith, K.; Reif, D. J. Org. Chem. 1993, 58, 705.

9 See highlight: Sibi, M. P.; Landais, Y. Angew. Chem., Int. Ed. 2013, 52, 3570.

10 Banks, R. E.; Mohialdinkhaffaf, S. N.; Lal, G. S.; Sharif, I.; Syvret, R. G. J. Chem. Soc. Chem. Commun. $1992,595$.

11 (a) Middleton, W. J. J. Org. Chem. 1975, 40, 574; (b) Middleton, W. J.; Bingham, E. M. Org. Synth. 1988, 50, 440.

12 (a) Hollingworth, C.; Gouverneur, V. Chem. Commun. 2012, 48, 2929; (b) Wu, J. Tetrahedron Lett. 2014, 55, 4289; (c) Lin, X.; Weng, Z. Dalton Trans. 2015, 44, 2021; (d) Yang, X.; Wu, T.; Phipps, R. J.; Toste, F. D. Chem. Rev. 2015, 115, 826.

13 Tang, P.; Wang, W.; Ritter, T. J. Am. Chem. Soc. 2011, 133, 11482.

14 (a) Sladojevich, F.; Arlow, S. I.; Tang, P.; Ritter, T. J. Am. Chem. Soc. 2013, 135, 2470; (b) Li, L.; Ni, C.; Wang, F.; Hu, J. Nat. Commun. 2016, 7, 13320.

15 (a) Kim, D. W.; Ahn, D.-S.; Oh, Y.-H.; Lee, S.; Kil, H. S.; Oh, S. J.; Lee, S. J.; Kim, J. S.; Ryu, J. S.; Moon, D. H.; Chi, D. Y. J. Am. Chem. Soc. 2006, 128, 16394; (b) Kim, D. W.; Jeong, H.-J.; Lim, S. T.; Sohn, M.-H. Tetrahedron Lett. 2010, 51, 432; (c) Liu, Y.; Chen, C.; Li, H.; Huang, K.-W.; Tan, J.; Weng, Z. Organometallics 2013, 32, 6587; (d) Dang, H.; Mailig, M.; Lalic, G. Angew. Chem. Int. Ed. $2014,53,6473$.

16 (a) Nishikata, T.; Ishida, S.; Fujimoto, R. Angew. Chem., Int. Ed. 2016, 55, 10008; (b) Chen, H.; Liu, Z.; Lv, Y.; Tan, X.; Shen, H.; Yu, H.-Z.; Li, C. Angew. Chem., Int. Ed. Doi:10.1001/anie.201708197.

17 (a) Watson, D. A.; Su, M.; Teverovskiy, G.; Zhang, Y.; Garcia-Fortanet, J.; Kinzel, T.; Buchwald, S. L. Science 2009, 325, 1661; (b) Mu, X.;

Zhang, H.; Chen, P.; Liu, G. Chem. Sci. 2014, 5, 275; (c) Fier, P. S.; Hartwig, J. F. J. Am. Chem. Soc. 2012, 134, 10795.

18 Pacheco, M. C.; Purser, S.; Gouverneur, V. Chem. Rev. 2008, 108, 1943.

19 Katcher, M. H.; Sha, A.; Doyle, A. G. J. Am. Chem. Soc. 2011, 133, 15902.

20 Hollingworth, C.; Hazari, A.; Hopkinson, M. N.; Tredwell, M.; Benedetto, E.; Huiban, M.; Gee, A. D.; Brown, J. M.; Gouverneur, V. Angew. Chem., Int. Ed. 2011, 50, 2613.

21 Topczewski, J. J.; Tewson, T. J.; Nguyen, H. M. J. Am. Chem. Soc. 2011, 133, 19318.

22 Larsson, J. M.; Pathipati, S. R.; Szabó, K. J. J. Org. Chem. 2013, 78, 7330.

23 Zhang, Z.; Wang, F.; Mu, X.; Chen, P.; Liu, G. Angew. Chem., Int. Ed. 2013, 52, 7549.

24 (a) Liu, W.; Huang, X.; Cheng, M.-J.; Nielsen, R. J.; Goddard, W. A.; Groves, J. T. Science 2012, 337, 1322; (b) Bloom, S.; Pitts, C. R.; Miller, D. C.; Haselton, N.; Holl, M. G.; Urheim, E.; Lectka, T. Angew. Chem., Int. Ed. 2012, 51, 10580.

25 (a) Tzirakis, M. D.; Lykakis, I. N.; Orfanopoulos, M. Chem. Soc. Rev. 2009, 38, 2609. (b) Protti, S.; Ravelli, D.; Fagnoni, M.; Albini, A. Chem. Commun. 2009, 7351. (c) Combs-Walker, L. A.; Hill, C. L. J. Am. Chem. Soc. 1992, 114, 938. (d) Renneke, R. F.; Pasquali, M.; Hill, C. L. J. Am. Chem. Soc. 1990, 112, 6585. 
26 Kee, C. W.; Chin, K. F.; Wong, M. W.; Tan, C.-H. Chem. Commun. 2014, 50, 8211.

27 (a) Xia, J.-B.; Zhu, C.; Chen, C. Chem. Commun. 2014, 50, 11701; (b) Xia, J.-B.; Ma, Y.; Chen, C. Org. Chem. Front. 2014,1 , 468.

28 (a) Halperin, S. D.; Fan, H.; Chang, S.; Martin, R. E.; Britton, R. Angew. Chem., Int. Ed. 2014, 53, 4690; (b) Halperin, S. D.; Kwon, D.;

Holmes, M.; Regalado, E. L.; Campeau, L.-C.; DiRocco, D. A.; Britton, R. Org. Lett. 2015, 17, 5200.

29 Pitts, C. R.; Bume, D. D.; Harry, S. A.; Siegler, M. A.; Lectka, T. J. Am. Chem. Soc. 2017, 139, 2208.

30 Zhang, X.; Guo, S.; Tang, P. Org. Chem. Front. 2015, 2, 806.

31 (a) Zhu, Q.; Ji, D.; Liang, T.; Wang, X.; Xu, Y. Org. Lett. 2015, 17, 3798; (b) Mao, J.; Yang, K.; Kurek, M.; Ge, H. Org. Lett. 2015, 17, 3738;

(c) Zhang, Q.; Yin, X.-S.; Zhang, S.-Q.; Shi, B.-F. J. Am. Chem. Soc. 2015, 137, 8219; (d) Zhu, R.-Y.; Tanaka, K.; Li, G.-C.; He, J.; Fu, H.-Y.; Li, S.-H.; Yu, J.-Q. J. Am. Chem. Soc. 2015, 137, 7067.

32 Braun, M.-G.; Doyle, A. G. J. Am. Chem. Soc. 2013, 135, 12990.

33 Chen, M. S.; White, M. C. J. Am. Chem. Soc. 2004, 126, 1346.

34 Bloom, S.; Knippel, J. L.; Holl, M. G.; Barber, R.; Lectka, T. Tetrahedron Lett. 2014, 55, 4576.

35 Amaoka, Y.; Nagatomo, M.; Inoue, M. Org. Lett. 2013, 15, 2160; (b) Bloom, S.; Pitts, C. R.; Woltornist, R.; Griswold, A.; Holl, M. G.; Lectka,

T. Org. Lett. 2013, 15, 1722; (c) Bloom, S.; Sharber, S. A.; Holl, M. G.; Knippel, J. L.; Lectka, T. J. Org. Chem. 2013, 78, 11082; (d) Huang, X.;

Liu, W.; Ren, H.; Neelamegam, R.; Hooker, J. M.; Groves, J. T. J. Am. Chem. Soc. 2014, 136, 6842; (e) Sun, H.; Zhang, Y.; Chen, P.; Wu, Y.-D.; Zhang, X.; Huang, Y. Adv. Synth. Catal. 2016, 358, 1946; (f) Bume, D. D.; Pitts, C. R.; Jokhai, R. T.; Lectka, T. Tetrahedron 2016, 72, 6031; (g) Xiang, M.; Xin, Z.-K.; Chen, B.; Tung, C.-H.; Wu, L.-Z. Org. Lett. 2017, 19, 3009.

36 Meanwell, M.; Nodwell, M. B.; Martin, R. E.; Britton, R. Angew. Chem., Int. Ed. 2016, 55, 13244.

37 Liu, W.; Groves, J. T. Angew. Chem., Int. Ed. 2013, 52, 6024.

38 Campbell, M. G.; Ritter, T. Chem. Rev. 2015, 115, 612.

39 (a) Sather, A. C.; Lee, H. G.; De La Rosa, V. Y.; Yang, Y.; Müller, P.; Buchwald, S. L. J. Am. Chem. Soc. 2015, 137, 13433; (b) Konovalov, A. I.; Gorbacheva, E. O.; Miloserdov, F. M.; Grushin, V. V. Chem. Commun. 2015, 51, 13527; (c) Fier, P. S.; Hartwig, J. F. J. Am. Chem. Soc. 2012, 134, 10795; (d) Sheppard, T. D. Org. Biomol. Chem. 2009, 7, 1043.

40 (a) Gamache, R. F.; Waldmann, C.; Murphy, J. M. Org. Lett. 2016, 18, 4522; (b) Ye, Y.; Schimler, S. D.; Hanley, P. S.; Sanford, M. S. J. Am. Chem. Soc. 2013, 135, 16292; (c) Mazzotti, A. R.; Campbell, M. G.; Tang, P.; Murphy, J. M.; Ritter, T. J. Am. Chem. Soc. 2013, 135, 14012; (d) Tang, P.; Furuya, T.; Ritter, T. R. J. Am. Chem. Soc. 2010, 132, 12150.

41 Hull, K. L.; Anani, W. Q.; Sanford, M. S. J. Am. Chem. Soc. 2006, 128, 7134.

42 Lou, S. -J.; Xu, D. -Q.; Xu, Z. -Y. Angew. Chem. Int. Ed. 2014, 53, 10330.

43 Lou, S. -J.; Chen, Q.; Wang, Y. -F.; Xu, D. -Q.; Du, X. -H.; He, J. -Q.; Mao, Y. -J.; Xu, Z. -Y. ACS Catal. 2015, 5, 2846.

44 Chan, K. S. L.; Wasa, M.; Wang, X.; Yu, J. -Q. Angew. Chem. Int. Ed. 2011, 50, 9081.

45 Chen, C.; Wang, C.; Zhang, J.; Zhao, Y. J. Org. Chem. 2015, 80, 942.

47 Trong, T.; Klimovica, K.; Daugulis, O. J. Am. Chem. Soc. 2013, 135, 9342.

48 Fier, P. S.; Hartwig, J. F. Science 2013, 342, 956. 